\title{
NOTAS AL SIMBOLISMO DEL OLIVO EN LA POESÍA DE RUBÉN DARÍO
}

\author{
FRANCISCO ESTÉVEZ \\ Universidad de Málaga
}

Ya de antiguo el olivo representa el árbol sagrado para los árabes, además del revestimiento sacro que, a través de Atenea, tiene en la descendencia grecolatina de nuestros pretéritos clásicos sobre los que se asientan las actuales ruinas europeas. Alrededor del olivar caminan también en paralelo una serie de ecos bíblicos aún detectables en cualquier manifestación simbólica como representa de manera privilegiada la célebre rama de olivo que una paloma triunfante llevará al arca de Noé a tierra firme de nuevo. Transmitida, de tal modo, a lo largo de ese gran bostezo que significó la Edad Media, la tradición española señala al olivo en los famosos diálogos medievales como lugar de recogimiento. Y, en efecto, la Historia de la lengua española acredita referencias al olivar y al aceite de oliva que permean los escritos de nuestra lengua, al menos, desde Alfonso X el Sabio en adelante y con cierta profusión según discernirá una historia crítico-etimológica de la terminología del aceite y de la oleocultura que desvele el tránsito suave pero seguro del «azeyte de azeytunas» al «aceite de oliva». Atenderé, sin embargo, en las siguientes páginas a la configuración literaria del olivo a través de su traslado icónico, prestando para ello lupa y oído a las referencias al olivar que menudean la obra poética de nuestro clásico Rubén Darío, el gran anticipador de toda la poesía en español del profuso siglo XX. Nos interesa pues la mirada ectópica que se proyecta desde el hispanismo hacia nuestras costas mediterráneas donde el olivo ha venido significando aquel mito sagrado de la creatividad. El olivo como centro 
del círculo mítico de nutrición que representan la vid y el agua, el pan y el vino, con ese claro pero profundo poso antropológico. Círculo que camina de lo mediterráneo a lo universal a través de la mirada ectópica de Rubén Darío. Aclaremos antes que todo texto literario, desde cualquiera de los tres polos clásicos (autor, texto, lector) que analicemos viene condicionado por un espacio y un tiempo que no siempre resultan ser el más obvio o el más cercano. Ciertamente en ese sentido es en el que Carmine Chiellino propuso el concepto de literatura como «parole erranti» ${ }^{2}$, es decir, unas palabras que transitan de un espacio cultural a otro espacio cultural como destacó, por otro lado, el teórico Tomás Albaladejo en su propuesta del concepto de «literatura ectópica» que ahora tanto nos concierne:

«Literatura ectópica» es una expresión que puede ser utilizada para denominar la literatura que ha sido escrita por autores que se han desplazado de su lugar de origen a otro lugar, implicando ese desplazamiento en muchos casos inmersión en una realidad lingüística distinta de la de origen e incluso cambio de lengua. Es la literatura que es producida fuera del lugar propio, fuera del espacio o territorio, en sentido geográfico y también en sentido cultural, en el que ha nacido o se ha formado el sujeto productor de dicha literatura. Es la literatura que está fuera del que sería su tópos propio y se sitúa en otro tópos, que también es lugar, espacio, pero distinto del previsible².

El olivo representa, en efecto y sin lugar a dudas, una de las más claras señales ectópicas en la literatura de Rubén Darío, quien no podía conocerlo vivencialmente hasta su llegada a Europa. Recordemos que ya en su misma etimología el olivo viene marcado por un carácter multicultural «Olea europea». Símbolo, tradición y modernidad se conjugan en los versos del nicaragüense a través del enramado del olivo, la configuración ectópica de la literatura hispánica sin ver la realidad del olivo más que en las imágenes proyectadas por la literatura española lo hacen de singular valor intercultural, puente de continentes. Conviene consignar brevemente que el olivo es símbolo de la paz y consagrado a Júpiter y Minerva por los romanos. Mantiene el mismo significado en muchos otros pueblos de Oriente y Europa. Así lo define, por ejemplo, el ya clásico Diccionario de símbolos de Juan Eduardo Cirlot:

OLIVo. Del latin vulgarl Olivus, lo emplea ya Berceo (Duelo, 52) figura en el glosario de Toledo (oleaster: oliva campensina) refiere Corominas en su Diccionario Crítico Etimológico castellano (pág. 248). La variedad de

${ }^{1}$ C. Chiellino, Parole erranti. Emigrazione, letteratura e interculturalità. Saggi 1995-2000, Cosmo Iannone, Isernia, 2001, pág. 143.

2 T. Albadalejo, «Sobre la literatura ectópica», en A. Bieniec, S. Lengl, S. Okou y N. Shchyhlebska (eds.), Rem tene, verba sequentur! Gelebte Interkulturalität. Festschrift zum 65. Geburtstag des Wissenschaftlers und Dichters Carmine/Gino Chiellino, Thelem, Dresde 2011, pág. 143. 
olivo llamada ocal, Villanueva de Cordoba, está ya documentada, por citar, en Fray Luis de león (siglo XI) cuando dice que las cosas no son todas iguales: ni las olivas grassass sin arreo

De un miso talle todas; que, si adviertes,

Hay luenga, hay ocal, hay las que creo

Que llaman pausia oliva, a quien ninguna

Iguala en amargura de aceituna ${ }^{3}$

En cuanto símbolo icónico como ser sagrado, el árbol aceituno ha sido objeto de un culto extraordinariamente difundido, vinculado estrechamente al culto de distintas deidades a las cuales se consagraban determinadas especies de árboles. De tal modo, el olivo es concebido como el árbol de Atenea, de la cual hereda también sus valores simbólicos al descender de una disputa entre Atenea y Poseidón (la victoria de la tierra, que posee claro trasunto en el pasaje del arca de Noé) y estar situado bajo su custodia. De tal modo, tocar indebidamente al olivo se consideraba sacrilegio: «todo perjuicio a estos árboles era susceptible de provocar una acusación de impiedad y desarraigarlos o abatirlos podía carrear una condena a muerte» ${ }^{4}$. De la amabilidad al éxito en las empresas, así como, en definitiva, la victoria, pasando en el judeocristianismo como símbolo de paz. No en vano la cruz de Jesús, casa de Dios, en suma, lleva en parte madera de olivo.

Sin embargo, la ignorancia se cierne sobre la cultura como la Xylella fastidiosa, una de las plagas más peligrosas conocidas en todo el mundo que ataca entre otras plantas al olivar, y una nota agria tiene la cultura en español para con sus clásicos literarios que la caracteriza de continuo con merma frente a otras tradiciones literarias como la anglosajona, la francesa o la italiana. Así, resulta la nuestra de un cuidado más precario y una deficitaria atención en la edición de sus clásicos a los que sólo de un tiempo a esta parte se les atiende con mayor cuidado y remedio. Claro es, en comparación con otras literaturas no es falta de cumbres, acaso sea el exceso de las mismas, unido a cierta nota distintiva del carácter hispano que, mezquino para con los suyos, dificulta el acceso a su literatura, descuida su pervivencia o zancadillea su futuro. Así con Rubén Darío. Por lo apenas señalado, conviene antes de entrar en materia revalorizar someramente la situación del clásico vate pues la reducción al tópico y la banalización de la personalidad poética han tenido en la figura del poeta de Metapa una encarnizada labor que ha convertido incluso en denuesto aquel de «el modernismo de Rubén Darío». Pues el nicaragüense fue ante todo un renovador de metro, de sintaxis, de palabra, incluso, sí, de espíritu, renovador de todo. El «libertador» será el nombre otorgado por Borges 5 . Y, en efecto, a

\footnotetext{
${ }^{3}$ J. E. Cirlot, Diccionario de símbolos, Siruela, Barcelona, 2004, pág. 340.

${ }^{4}$ J. Chevalier, Diccionario de los símbolos, Herder, Barcelona, pág. 121.

5 J. L. Borges, «Mensaje en honor de Rubén Darío», II Congreso Latinoamericano de Escritores, El Despertar Americano, vol. I (2), México, mayo de 1967, pág. 9.
} 
partir de él no se podrá escribir poesía en español sin considerar su labor. El fino crítico que fuera Juan Ramón Jiménez se dio cuenta muy pronto del valor literario que del Nuevo Mundo arribaba. Para el primer número de la elegante revista Helios, en abril de 1903, redacta una «Reseña de Peregrinaciones» que exalta de la siguiente manera al vate: «Rubén Darío, uno de los más grandes poetas españoles de todos los tiempos y de los menos comprendidos y más injustamente atacados por enanos literarios $»^{6}$. Y así puede seguir si no lo ponemos en limpio. Rubén Darío fue, sin duda, el último y más sobresaliente de los románticos y el primer moderno en lengua española. Es misión de la filología ponerlo en lectura cómoda, limpia de erratas y fiel, al pie de la calle de los lectores, que han de ser muchos. Muchas ediciones se han arrojado el nombre de «críticas» sin serlas al punto o no llegando siquiera a ser una edición depurada y bien anotada. Sin embargo, hay valiosos acercamientos parciales a tan compleja edición crítica de la poesía entera. Todo ello es imprescindible para posibilitar una revalorización de la lectura real de la obra rubendariana y acometer estudios temáticos como el de las siguientes líneas.

Como somero repaso por entre la intrincada selva poética del centroamericano y para manifestar la tarea filológica a emprender valdrá aquí fijarnos en el siguiente cotejo en los libros poéticos completos de Rubén Darío ${ }^{7}$. Tras consulta de los términos: olivo, olivar y aceituna se encuentran las referencias de «olivo» en las página 493, 510, 683, 706, 714, 734, 742; de «olivar» en la página $755 \mathrm{y}$, finalmente, de «aceituna» en las páginas 327-331, 755 .

En Prosas profanas y otros poemas:

\section{MARINA}

Como al fletar mi barca con destino a Citeres saludara a las olas, contestaron las olas con un saludo alegre de voces de mujeres. Y los faros celestes prendían sus farolas,

5 mientras temblaba el suave crepúsculo violeta. «Adiós — dije— países que me fuisteis esquivos; adiós peñascos enemigos del poeta; adiós costas en donde se secaron las viñas y cayeron los Términos en los bosques de olivos.

10 Parto para una tierra de rosas y de niñas, para una isla melodiosa

${ }^{6}$ Véase J. R. Jiménez, Mi Rubén Dario (ed. de A. Sánchez Romerazo), Fundación Juan Ramón Jiménez, Moguer, 1990, págs. 166-167.

${ }^{7}$ Seguimos aquí nuestra reciente edición que aúna en edición crítica los libros poéticos completos de Darío y, en especial, respeta la lección del poeta, enmienda erratas de editores y correcciones erróneas de editores anteriores: «Yo soy aquel que ayer no más decía» Libros poéticos completos (coord. de R. de la Fuente y F. Estévez; ed. crítica de A. Acereda, R. de la Fuente Ballesteros, F. Estévez y J. Pascual), J. Fondo de Cultura Económica, Madrid, 2018. 
donde más de una musa me ofrecerá una rosa».

Mi barca era la misma que condujo a Gautier y que Verlaine un día para Chipre fletó,

15 y provenía de

el divino astillero del divino Watteau.

Y era un celeste mar de ensueño,

y la luna empezaba en su rueca de oro

a hilar los mil hilos de su manto sedeño.

20 Saludaba mi paso de las brisas el coro

y a dos carrillos daba redondez a las velas.

En mi alma cantaban celestes filomelas cuando oí que en la playa sonaba como un grito.

Volví la vista y vi que era una ilusión

25 que dejara olvidada mi antiguo corazón.

Entonces, fijo del azur en lo infinito, para olvidar del todo las amarguras viejas, como Aquiles ${ }^{8}$ un día, me tapé las orejas. Y les dije a las brisas: «Soplad, soplad más fuerte;

30 soplad hacia las costas de la isla de la Vida».

$\mathrm{Y}$ en la playa quedaba desolada y perdida una ilusión que aullaba como un perro a la Muerte.

(pág 493)

El poeta emprende viaje simbólico a Citera, la famosa isla griega prendada de mitología y topos clásicos del arte y la poesía, como se desprende, por ejemplo, de la lectura culturalista que propone el poema de Guillermo Carnero dedicado al «El embarco para Citerea»». Aquí, en nuestro poema rubendariano, el símbolo del hogar queda fijado y condensado por ese «bosque de olivos», hogar especial pues en la simbología cristiana el olivo designa, en definitiva, el paraíso de los elegidos. El abandono del Paraíso de los Poetas y la llegada «hacia las cosas de la isla de la Vida» sería pues el tema del poema desvelado por la simbología del olivo en estos versos.

En Cantos de vida y esperanza de 1905 encontramos el poema «Al rey Oscar», publicado originalmente el 8 de abril de 1899 en la revista La Ilustración Española y Americana, cuyo tema central es un peculiar homenaje a la cultura española y para el que Rubén Darío se sirve de la traslación del símbolo de la rama de olivo en pico de paloma por tallo de rosa de fuego, variando ectópicamente el simbolismo de paz a compromiso en la guerra entre la cultura hispana y la española respecto a los acontecimientos de 1898:

\footnotetext{
8 EMS (1977), JO: «Ulises».

9 Para un análisis del poema y sus intertextos véase la propuesta hermenéutica del propio autor en F. Estévez, Poetas por sí mismos, Biblioteca Nueva, Madrid, 2007, págs. 39-50.
} 
Así, sire, en el aire de la Francia nos llega La paloma de plata de Suecia y de Noruega, que trae en vez de olivo una rosa de fuego.

Un búcaro latino, un noble vaso griego recibirá el regalo del país de la nieve.

Que a los reinos boreales el patrio viento lleve otra rosa de sangre y de luz españolas; pues sobre la sublime hermandad de las olas, al brotar tu palabra, un saludo le envía al sol de Medianoche el sol del Mediodía.

Si Segismundo siente pesar, Hamlet se inquieta.

El Norte ama las palmas; y se junta el poeta del fjord con el del Carmen, porque el mismo oriflama es de azur. Su divina cornucopia derrama sobre el polo y el trópico la Paz; y el orbe gira en un ritmo uniforme por una propia lira: el Amor. Allá surge Sigurd que al Cid se aúna, cerca de Dulcinea brilla el rayo de luna, y la musa de Bécquer del ensueño es esclava bajo un celeste palio de luz escandinava.

$$
[\ldots]
$$

Hete aquí la visión simbólica clásica asignada al olivo desde la antigüedad clásica y que Rubén Darío respecta y proyecta a su época para enfrentar a la violencia de la «rosa de fuego». En semejante forma y manera se presenta en Poemas del Otoño y otros poemas de 1910 la siguiente

\section{RETORNO}

El retorno a la tierra natal ha sido tan sentimental, y tan mental, y tan divino, que aún las gotas del alba cristalinas están en el jazmín de ensueño, de fragancia y de trino.

$$
[\ldots]
$$

En el lugar en donde tuve la luz y el bien, ¿qué otra cosa podría sino besar el manto a mi Roma, mi Atenas o mi Jerusalén? 
A través de las páginas fatales de la Historia,

55 nuestra tierra está hecha de vigor y de gloria, nuestra tierra está hecha para la Humanidad.

Pueblo vibrante, fuerte, apasionado, altivo; pueblo que tiene la conciencia de ser vivo, y que, reuniendo sus energías en haz

60 portentoso, a la Patria vigoroso demuestra que puede bravamente presentar en su diestra el acero de guerra o el olivo de paz

(pág. 706)

del mismo poemario se registra la siguiente aparición del árbol para rematar las claves mediterráneas que le interesan resaltar al nicaragüense en el poema

\section{A Mistral}

¡Mistral! La copa santa llena de santo vino alza el mundo por ti,

y lleva nueva sangre al corazón latino su líquido rubí.

5 ¡Gran patriarca! ¡Tu canto lleva el mistral sonoro, canto de amor y fe,

y alza su palma lírica tu Provenza de oro por su gran Capoulié!

Provenza, que cultiva sus olivos y parras, cuida el verde laurel, y al glorioso son de liras y cigarras te corona con él

(pág. 714)

De máxima carga simbólica tiene en el libro Canto a la Argentina el olivo, con el que caracteriza

\section{Canto a la Argentina}

¡Argentina! ¡Argentina!

¡Argentina! El sonoro

viento arrebata la gran voz de oro.

Ase la fuerte diestra la bocina,

5 y el pulmón fuerte, bajo los cristales 
del azul, que han vibrado,

lanza el grito: Oíd, mortales, oid el grito sagrado.

\section{$[\ldots]$}

Hombres de España poliforme, finos andaluces sonoros,

125 amantes de zambras y toros, astures que entre peñascos aprendisteis a amar la augusta Libertad, elásticos vascos como hechos de antiguas raíces,

130 raza heroica, raza robusta, rudos brazos y altos cervices; hijos de Castilla la noble rica de hazañas ancestrales; firmes gallegos de roble;

135 catalanes y levantinos que heredasteis los inmortales fuegos de hogares latinos; iberos de la península que las huellas del paso de Hércules

140 visteis en el suelo natal: ¡he aquí la fragante campaña en donde crear otra España en la Argentina universal!

(pág. 734)

y más adelante

Cantaré la Paz sobre todo.

795 Huya el Demonio perverso, huya el Demonio beodo que incendia en mal el universo, desaparezcan las furias que con sangre de los ejércitos

800 empurpuraron las centurias; que no más rujan los tigres marciales sino de alegría, y que a la Paz se alce un templo como aquel que dando un ejemplo

805 insigne Augusto romano ordenara elevar un día. El industrioso ciudadano el ramo de olivo venere: que tenga sus armas listas, 
810 no para inhumanas conquistas, mas para defender su tierra donde por la patria se muere. ¡Guerra, pues, tan sólo a la guerra! Paz, para que el pensamiento

815 domine el globo, y vaya luego, cual bíblico carro de fuego, de firmamento en firmamento. ¡Paz para los creadores, descubridores, inventores,

820 rebuscadores de verdad; paz a los poetas de Dios, paz a los activos y a los hombres de buena voluntad!

(pág. 742)

En esta última referencia la mirada ectópica de Rubén Darío aúna las distintas aristas simbólicas que la tradición ha conjugado como árbol sagrado, en esa veneración que demanda del «industrioso ciudadano», también como hogar, espacio, «su tierra»y como símbolo de la prosperidad (aceite) y, por fin, deviene en símbolo de paz unido a la paloma que porta a Noé el final del castigo divino y la paz con el hombre a través de un pequeño ramo de olivo. «Si puedo ver en tu puerta madera de olivo dorada, te llamaría al instante templo de Dios», escribe Angelus Silesius, inspirándose en la descripción del templo de Salomón ${ }^{10}$. Símbolo pues de paz como imploran los versos finales del poema de Rubén Darío que ponen colofón a estas páginas:

¡Paz para los creadores, descubridores, inventores,

820 rebuscadores de verdad; paz a los poetas de Dios, paz a los activos y a los hombres de buena voluntad!

${ }^{10}$ J. Chevalier, op. cit., pág. 121. 
